\title{
Short- and long-term outcomes in patients undergoing valve surgery with end-stage renal failure receiving chronic hemodialysis
}

\author{
Vinod H. Thourani, MD, ${ }^{\text {a }}$ Eric L. Sarin, MD, ${ }^{\text {a }}$ Patrick D. Kilgo, MS, ${ }^{b}$ Omar M. Lattouf, MD, PhD, ${ }^{a}$ \\ John D. Puskas, MD, ${ }^{\mathrm{a}}$ Edward P. Chen, MD, ${ }^{\mathrm{a}}$ and Robert A. Guyton, MD ${ }^{\mathrm{a}}$
}

\begin{abstract}
Objectives: The objective of this study was to evaluate the effect of chronic preoperative hemodialysis for endstage renal failure in patients undergoing valve surgery.

Methods: A retrospective review of patients undergoing primary valve with or without coronary artery bypass surgery from 1996 to 2008 at a US academic center was performed. The patients were divided into two groups: group 1 underwent valve surgery without preoperative dialysis $(n=5084)$ and group 2 underwent valve surgery with preoperative dialysis $(\mathrm{n}=224)$. The outcomes were evaluated using multivariate regression analysis, and long-term survival was assessed with Kaplan-Meier plots.
\end{abstract}

Results: The patients in group 2 were younger $(P<.001)$, were more likely women $(P=.04)$, and presented with New York Heart Association class III-IV $(P<.001)$. The ejection fraction was similar between the two groups $(P=.36)$. The adjusted perioperative morbidity was similar between the two groups for stroke $(P=.79)$ and myocardial infarction $(P=.68)$. Resource use (postoperative length of stay) was greater in group 2 $(P<.001)$, as was in-hospital mortality (group $1,263 / 5084[5.2 \%]$ vs group $2,41 / 224[18.3 \%] ; P<.001)$. The 1-, 5-, and 10-year survival was less in group $2(P<.001)$; the median survival was 12 or more years in group 1 and 1.8 years in group 2. Preoperative end-state renal disease, among others, show a trend as an independent predictor for short-term mortality and was a significant predictor for long-term mortality.

Conclusions: In this large cohort of patients, preoperative dialysis conferred a high risk of perioperative morbidity and mortality and poor long-term survival after valve surgery. Risk stratification and future research efforts should focus on more precise identification of the benefits of valve surgery in this high-risk patient population. (J Thorac Cardiovasc Surg 2012;144:117-23)

The prevalence of end-stage renal disease (ESRD) continues to increase in the United States. The 2009 annual data report from the United States Renal Data System revealed that as of 2007, 527,282 patients had ESRD in the United States. ${ }^{1}$ The projections from this report estimate that the prevalence of ESRD in the United States will approach 775,000 by 2020 . This steady increase in patients with ESRD parallels similar trends seen around the world. $^{2,3}$ Furthermore, the United States Renal Data System data report revealed that the prevalence rates are increasing most rapidly among patients aged 65 years and older.

\footnotetext{
From the Clinical Research Unit, ${ }^{a}$ Division of Cardiothoracic Surgery, Joseph B. Whitehead Department of Surgery, Emory University School of Medicine, Atlanta, $\mathrm{Ga}$; and Department of Biostatistics, ${ }^{\mathrm{b}}$ Emory University Rollins School of Public Health, Atlanta, Ga.

The funding for this report was internal funds from the Division of Cardiothoracic Surgery Clinical Research Unit.

Disclosures: Authors have nothing to disclose with regard to commercial support.

Received for publication Feb 4, 2011; revisions received July 4, 2011; accepted for publication July 26, 2011; available ahead of print Aug 26, 2011.

Address for reprints: Vinod H. Thourani, MD, Department of Surgery, Division of Cardiothoracic Surgery, Emory University School of Medicine, 550 Peachtree Street, Crawford Long Hospital, 6th Floor, Medical Office Tower, Atlanta, GA 30308 (E-mail: vthoura@emory.edu).

$0022-5223 / \$ 36.00$

Copyright (C) 2012 by The American Association for Thoracic Surgery doi:10.1016/j.jtcvs.2011.07.057
}

Cardiovascular disease and its complications are the most common cause of death among patients with ESRD, especially among the older age groups. The multiple shared risk factors that lead to the development of cardiovascular and renal disease cause the two disease processes to often exist and progress in concert with one another. ${ }^{4,5}$ Once patients have developed ESRD and dialysis dependence, they have often already developed significant symptoms related to coronary artery disease, heart failure, and valverelated cardiac abnormalities. ${ }^{6}$

Although multiple studies have examined the outcomes in patients with ESRD undergoing cardiac surgery, many of these studies examined the outcomes after all types of cardiac surgery and did not focus solely on the outcomes after valve-related procedures. ${ }^{3,7-16}$ Therefore, the purpose of the present study was to investigate the short- and long-term outcomes in patients requiring preoperative dialysis and undergoing cardiac valve surgery.

\section{METHODS}

The present retrospective, cohort study sought to determine the effect of a preoperative diagnosis of renal failure requiring dialysis on the clinical outcomes after cardiac valve surgery. The patients were classified into two groups - those requiring dialysis preoperatively and those who did not. The patients were identified by querying the institutional Society of Thoracic Surgeons (STS) Adult Cardiac Database for consecutive qualified 


\author{
Abbreviations and Acronyms \\ $\mathrm{CABG}=$ coronary artery bypass grafting \\ $\mathrm{CI}=$ confidence interval \\ $\mathrm{CPB}=$ cardiopulmonary bypass \\ $\mathrm{ESRD}=$ end-stage renal disease \\ STS $=$ Society of Thoracic Surgeons
}

patients treated at Emory University Healthcare Hospitals from January 1, 1996 to December 31, 2008. Patients with concomitant coronary artery bypass grafting (CABG) were included and those with previous valve surgery, those with previous $\mathrm{CABG}$, and those undergoing salvage treatment were excluded.

During this period, 5308 qualified patients underwent valve surgery. Of these, 224 patients $(4.2 \%)$ were receiving preoperative dialysis. Of the 5084 patients not receiving dialysis, 305 patients $(6.0 \%)$ were diagnosed with nondialysis-dependent chronic renal failure and were categorized in the "no preoperative dialysis" group. The extracted records included the demographic data, pre-existing conditions, and clinical outcomes. The study was formally approved by the Emory University institutional review board in compliance with Health Insurance Portability and Accountability Act regulations and the Declaration of Helsinki. The institutional review board waived individual patient consent for these patients.

\section{Interventions, Surgeons, and Surgical Technique}

Each patient underwent a single surgical session performed at the discretion of any of 20 faculty surgeons. Cardiac catheterization was performed in all patients older than 40 years or in younger patients with risk factors for coronary artery disease. The nephrology service was consulted before surgical intervention and treated the patients for renal replacement and electrolyte management in all patients requiring preoperative dialysis. Standard cardiopulmonary bypass (CPB) techniques for valve operations were used in all patients. The surgical approach, valve prosthesis or repair techniques, and conduct of $\mathrm{CPB}$ and myocardial protection were left to the discretion of the attending cardiac surgeon. Typically, conventional CPB was performed using roller head pumps, membrane oxygenators, cardiotomy suction, arterial filters, cold antegrade and retrograde blood cardioplegia, and moderate systemic hypothermia $\left(32^{\circ}\right.$ to $\left.34^{\circ} \mathrm{C}\right)$. The operative field was routinely flooded with carbon dioxide, and de-airing maneuvers were performed in all cases before releasing the cross-clamp. In those requiring preoperative dialysis, postoperative extubation was generally performed after dialysis.

\section{Long-Term Follow-up}

The Social Security Death Index is a public, national database of death records extracted from the United States Social Security Administration's Death Master File Extract. Patients with a Social Security number who have died after 1963 and whose death has been reported to the Social Security Administration will be listed in the Social Security Death Index. For all patients who died before the cutoff date of June 30, 2008, a mortality date was provided, allowing creation of Kaplan-Meier long-term survival curves. The cause of death was not available for any of the patients; thus, the present study described all-cause long-term mortality.

\section{Variables of Interest}

Before analysis, 19 preoperative risk factors were harvested from the STS database (Table 1). Standard STS definitions for each risk factor and outcome were used. Race was dichotomized as either white or nonwhite. Chronic lung disease (chronic obstructive pulmonary disease) was ordinally measured in some latter years and dichotomously
TABLE 1. Preoperative demographics and clinical characteristics by dialysis status

\begin{tabular}{|c|c|c|c|}
\hline Characteristic & $\begin{array}{c}\text { No preoperative } \\
\text { dialysis } \\
(\mathbf{n}=\mathbf{5 0 8 4}) \\
\end{array}$ & $\begin{array}{c}\text { Preoperative } \\
\text { dialysis } \\
(n=224) \\
\end{array}$ & $P$ value \\
\hline Age (y) & & & $<.001$ \\
\hline Mean \pm SD & $61.2 \pm 14.8$ & $54.1 \pm 14.0$ & \\
\hline Median & 63 & 55 & \\
\hline Female gender (n) & $2172(42.7)$ & $111(49.6)$ & 0.043 \\
\hline Status (n) & & & $<.001$ \\
\hline Elective & $4017(79.0)$ & $143(63.8)$ & \\
\hline Urgent & $849(16.7)$ & $64(28.6)$ & \\
\hline Emergent & $216(4.3)$ & $17(7.6)$ & \\
\hline White race (n) & $3523(80.1)$ & $58(31.5)$ & $<.001$ \\
\hline Hypertension (n) & $3264(64.2)$ & $213(95.1)$ & $<.001$ \\
\hline Ejection fraction (n) & & & .36 \\
\hline Mean \pm SD & $52.8 \pm 13.1$ & $53.7 \pm 13.3$ & \\
\hline Median & 55 & 55 & \\
\hline NYHA class III or IV (n) & $683(19.4)$ & $56(31.5)$ & $<.001$ \\
\hline Previous stroke & $370(7.3)$ & $48(21.4)$ & $<.001$ \\
\hline Chronic lung disease & & & .40 \\
\hline None & $2623(81.5)$ & $137(83.5)$ & \\
\hline Mild & $379(11.8)$ & $13(7.9)$ & \\
\hline Moderate & $85(2.6)$ & $6(3.7)$ & \\
\hline Severe & $130(4.0)$ & $8(4.9)$ & \\
\hline Diabetes & $933(18.45)$ & $87(38.8)$ & $<.001$ \\
\hline Chronic lung disease & $594(11.7)$ & $27(12.1)$ & .87 \\
\hline Previous myocardial infarction & $798(15.7)$ & $46(20.5)$ & .053 \\
\hline Cerebrovascular disease & $647(12.7)$ & $53(23.7)$ & $<.001$ \\
\hline Peripheral vascular disease & $301(5.9)$ & $42(18.8)$ & $<.001$ \\
\hline Preoperative serum creatinine & & & $<.001$ \\
\hline Mean \pm SD & $1.14 \pm 0.61$ & $7.34 \pm 3.17$ & \\
\hline Median & 1.00 & 7.05 & \\
\hline Chronic renal insufficiency & $305(6.0)$ & $224(100.0)$ & $<.001$ \\
\hline Infectious endocarditis & $327(6.4)$ & $78(34.8)$ & $<.001$ \\
\hline Current smoker & $1756(34.5)$ & $83(37.1)$ & .44 \\
\hline Preoperative IABP & $42(0.8)$ & $2(0.9)$ & .91 \\
\hline Immunosuppressive therapy & $250(4.9)$ & $33(14.7)$ & $<.001$ \\
\hline $\begin{array}{l}\text { STS predicted risk of } \\
\text { mortality }(\%)\end{array}$ & & & $<.001$ \\
\hline Mean \pm SD & $4.1 \pm 4.2$ & $14.8 \pm 9.2$ & \\
\hline Median & 2.8 & 13.0 & \\
\hline
\end{tabular}

measured in earlier years; in the present study, it was dichotomized. The new York Hospital Association heart failure classification was dichotomized as class III-IV or I-II. The primary outcomes examined in the present study were in-hospital mortality and long-term survival; other endpoints of interest included permanent stroke (cerebrovascular accident), myocardial infarction, the composite endpoint for any of these major adverse cardiac and cerebrovascular events, and operative re-intervention.

\section{Data Management and Statistical Analysis}

All data for the consecutive patients were entered into a computerized surgical database, using the fields and definitions of the STS National Adult Cardiac Database. Checks for data quality were used at both the 
institutional level and before final entry into the STS National Adult Cardiac Database.

To statistically evaluate the effects of preoperative dialysis on inhospital mortality, a multivariate logistic regression model was constructed. The model contained preoperative covariates to adjust for potential selection bias; age, gender, body mass index, renal failure, heart failure, ejection fraction, presence of concomitant $\mathrm{CABG}$, infectious endocarditis, previous stroke, diabetes mellitus, and chronic lung disease. Adjusted odds ratios associated with preoperative dialysis and other covariates, along with the $95 \%$ confidence intervals (CIs), were computed.

Long-term survival comparisons were made using adjusted Cox proportional hazards regression (PHREG) models and Kaplan-Meier productlimit estimates (unadjusted). Kaplan-Meier curves were generated that provide survival estimates at postoperative points. Differences between dialysis status were determined using log-rank tests. These estimates included operative deaths.

Adjusted long-term survival comparisons were made using PHREG to model the instantaneous hazard of death as a function of dialysis, adjusted for age, gender, body mass index, renal failure, heart failure, ejection fraction, presence of concomitant $\mathrm{CABG}$, infectious endocarditis, previous stroke, diabetes mellitus, and chronic lung disease. The proportional hazards assumption was verified using a correlation analysis of the Schoenfeld residuals and ranked follow-up time. Adjusted hazard ratios were generated for each model term, along with the $95 \%$ CIs.

The data were managed and analyzed using SAS, version 9.1 (SAS Institute, Cary, NC). Unadjusted comparisons were performed using chisquare tests and two-sample $t$ tests for categorical and numerical predictors, respectively. All statistical tests were two-sided using an $\alpha=0.05$ level of significance.

\section{RESULTS}

\section{Preoperative and Operative Characteristics}

A total of 5308 patients underwent valve surgery at a single academic institution and constituted the study group. The patients were divided into two groups: group 1 received no preoperative dialysis $(\mathrm{n}=5084)$ and group 2 received preoperative dialysis $(n=224)$. The preoperative characteristics are listed in Table 1. Despite being younger and with equally preserved ejection fractions, patients requiring preoperative dialysis were uniformly sicker preoperatively compared with the nondialysis patients. This was evident in the STS Predicted Risk of In-hospital Mortality of $4.1 \%$ versus $14.8 \%(P<.001)$.

Table 2 describes the operative procedures according to the need for preoperative chronic dialysis. In both groups, the most common surgery was concomitant valve and $\mathrm{CABG}$; and aortic valve replacement was the most common in those not requiring CABG. Bioprosthetic valve implantation was more commonly used in the dialysis patients. The aortic cross-clamp and CPB times were both significantly longer for the dialysis patients.

\section{In-Hospital Morbidity and Mortality}

The unadjusted in-hospital outcomes are listed in Table 3. In those patients undergoing dialysis preoperatively, inhospital morbidity was overwhelming increased compared with those without preoperative dialysis. Furthermore, resource use as indicated by the time on a ventilator and the
TABLE 2. Operative characteristics by dialysis status

\begin{tabular}{|c|c|c|c|}
\hline Operative data & $\begin{array}{c}\text { No preoperative } \\
\text { dialysis } \\
(n=\mathbf{5 0 8 4})\end{array}$ & $\begin{array}{c}\text { Preoperative } \\
\text { dialysis } \\
(\mathbf{n}=\mathbf{2 2 4})\end{array}$ & $P$ valu \\
\hline $\begin{array}{l}\text { Isolated aortic valve } \\
\text { replacement }\end{array}$ & $1446(28.4)$ & 64 (28.6) & .97 \\
\hline $\begin{array}{l}\text { Isolated mitral valve repair or } \\
\text { replacement }\end{array}$ & $1149(22.6)$ & $38(17.0)$ & .048 \\
\hline $\begin{array}{l}\text { Any valve plus concomitant } \\
\text { CABG }\end{array}$ & $1672(32.9)$ & $65(29.0)$ & .23 \\
\hline $\begin{array}{l}\text { Other isolated valve or combo } \\
\text { valves }\end{array}$ & $817(16.1)$ & $57(25.5)$ & $<.001$ \\
\hline Bioprosthetic valve & $2500(49.2)$ & $128(57.1)$ & .02 \\
\hline Body mass index $\left(\mathrm{kg} / \mathrm{m}^{2}\right)$ & & & .057 \\
\hline Mean \pm SD & $27.8 \pm 5.9$ & $26.9 \pm 6.7$ & \\
\hline Median & 26.9 & 25.8 & \\
\hline Aortic cross-clamp time (min) & & & $<.001$ \\
\hline Mean \pm SD & $93.5 \pm 38.0$ & $104.6 \pm 40.4$ & \\
\hline Median & 86.0 & 98.0 & \\
\hline $\begin{array}{l}\text { Cardiopulmonary bypass } \\
\text { time ( } \mathrm{min})\end{array}$ & & & $<.001$ \\
\hline Mean \pm SD & $131.3 \pm 49.3$ & $144.2 \pm 50.7$ & \\
\hline Median & 121 & 137 & \\
\hline $\begin{array}{l}\text { Intraoperative IABP } \\
\text { implanted } \\
\end{array}$ & $258(5.1)$ & $13(4.8)$ & .63 \\
\hline
\end{tabular}

Data presented as numbers (\%), unless otherwise noted. $C A B G$, Coronary artery bypass grafting; $S D$, Standard deviation; $I A B P$, Intra-aortic balloon counterpulsation.

intensive care unit and overall postoperative length of stay was significantly greater for those with preoperative dialysis. The in-hospital mortality rate for the entire cohort was $5.7 \%(\mathrm{n}=304)$. Mortality was significantly greater for those with preoperative dialysis $(18.3 \%$ vs $5.2 \%$; $P<.0001)$. The observed STS Predicted Risk of Inhospital Mortality expected ratio was 1.27 for those without preoperative dialysis compared with 1.24 for those with preoperative dialysis. Among the major cardiac adverse events, only in-hospital death was statistically greater for the dialysis patients (Table 4). However, on multivariate logistic regression analysis (Table 5), chronic preoperative dialysis showed a trend toward, but was not an independent predictor for, in-hospital mortality (odds ratio, 1.51; 95\% CI, 0.96 to $2.39 ; P=.08$ ). Other covariates included advanced age, female gender, nondialysis renal failure, coronary artery disease requiring $\mathrm{CABG}$, and endocarditis.

\section{Long-Term Mortality}

The median follow-up for all patients was 4.4 years. The survival estimates for each group are listed in Table 6 and revealed that those patients undergoing preoperative dialysis had significantly reduced all-cause mid- and longterm survival. Graphically, this is represented in the Kaplan-Meier curves (Figures 1 to 5). In an all patient subgroup analysis, the patients with preoperative dialysis 
TABLE 3. Unadjusted short-term postoperative outcomes by dialysis status

\begin{tabular}{|c|c|c|c|}
\hline Outcome & $\begin{array}{c}\text { No preoperative } \\
\text { dialysis } \\
(\mathbf{n}=\mathbf{5 0 8 4})\end{array}$ & $\begin{array}{c}\text { Preoperative } \\
\text { dialysis } \\
(\mathbf{n}=\mathbf{2 2 4})\end{array}$ & $P$ value \\
\hline Myocardial infarction & $24(0.5)$ & $3(1.3)$ & .074 \\
\hline Stroke & $151(3.0)$ & $14(6.3)$ & .006 \\
\hline Mediastinitis & $39(0.8)$ & $8(3.6)$ & $<.001$ \\
\hline Renal failure & $363(7.1)$ & - & - \\
\hline Dialysis & $140(2.8)$ & - & - \\
\hline Septicemia & $147(2.9)$ & $26(11.6)$ & $<.001$ \\
\hline $\begin{array}{l}\text { Heart block requiring } \\
\text { pacemaker }\end{array}$ & $164(3.2)$ & $10(4.7)$ & .31 \\
\hline MSOF & $86(1.7)$ & $16(7.1)$ & $<.001$ \\
\hline $\begin{array}{l}\text { Re-exploration for } \\
\text { hemorrhage }\end{array}$ & $300(5.9)$ & $19(8.5)$ & .11 \\
\hline Postoperative pneumonia & $324(6.4)$ & $34(15.2)$ & $<.001$ \\
\hline Postoperative ventilator (h) & & & $<.001$ \\
\hline Mean \pm SD & $43 \pm 127$ & $122 \pm 218$ & \\
\hline Median & 9.1 & 33.2 & \\
\hline Prolonged ventilation & $744(14.6)$ & $106(47.3)$ & $<.001$ \\
\hline Postoperative IABP insertion & $38(0.8)$ & $1(0.5)$ & .61 \\
\hline Gastrointestinal complication & $219(4.3)$ & $32(14.3)$ & $<.001$ \\
\hline Total initial ICU LOS (h) & & & $<.001$ \\
\hline Mean $\pm \mathrm{SD}$ & $103 \pm 173$ & $247 \pm 304$ & \\
\hline Median & 46 & 121 & \\
\hline Postoperative LOS (d) & & & $<.001$ \\
\hline Mean \pm SD & $9.1 \pm 9.0$ & $17.4 \pm 16.6$ & \\
\hline Median & 6.0 & 11.0 & \\
\hline In-hospital mortality & $263(5.2)$ & $41(18.3)$ & $<.001$ \\
\hline STS PROM $(\%)$ & & & $<.001$ \\
\hline Mean \pm SD & $4.1 \pm 4.2$ & $14.8 \pm 9.2$ & \\
\hline Median & 2.8 & 13.0 & \\
\hline O/E mortality & 1.27 & 1.24 & - \\
\hline
\end{tabular}

Data presented as numbers (\%), unless otherwise noted. $M S O F$, Multisystem organ failure; IABP, Intra-aortic balloon counterpulsation; ICU, Intensive care unit; $L O S$, Length of stay; STS, Society of Thoracic Surgeons; PROM, Predicted risk of mortality; $O / E$, observed to expected.

had reduced survival. In the unadjusted survival analysis for long-term mortality (Table 7), the instantaneous hazard for death was 4.67 times greater if the patient required preoperative dialysis. After an age adjustment was performed, it was shown that younger patients requiring preoperative dialysis had worse survival (hazard ratio, 6.54; 95\% CI, 5.41 to 7.89 ). When a full adjustment was performed using 11 covariates, preoperative chronic dialysis was still
TABLE 5. Significant preoperative predictors of in-hospital survival from multivariate survival analysis

\begin{tabular}{lcc}
\hline \multicolumn{1}{c}{ Preoperative variable } & Odds ratio $(95 \%$ CI $)$ & $\boldsymbol{P}$ value \\
\hline Age & $1.03(1.02-1.04)$ & $<.001$ \\
Chronic lung disease & $0.99(0.73-1.34)$ & .94 \\
CVA & $1.31(0.95-1.81)$ & .10 \\
EF & $1.00(0.988-1.004)$ & .32 \\
Infectious endocarditis & $1.62(1.11-2.35)$ & .012 \\
Female gender & $1.59(1.30-1.95)$ & $<.001$ \\
Heart failure & $0.91(0.74-1.13)$ & .40 \\
Renal failure & $2.62(1.90-3.62)$ & $<.001$ \\
Renal failure requiring dialysis & $1.51(0.96-2.39)$ & .08 \\
CAD requiring CABG & $1.47(1.18-1.82)$ & $<.001$ \\
Body mass index & $1.01(0.993-1.024)$ & .29 \\
Diabetes & $1.04(0.82-1.33)$ & .74 \\
\hline
\end{tabular}

$C I$, Confidence interval; $C V A$, Cerebrovascular accident; $E F$, Ejection fraction; $C A D$, Coronary artery disease; $C A B G$, Coronary artery bypass grafting.

associated with reduced long-term survival (hazard ratio, $2.34 ; 95 \%$ CI, 1.83 to 2.99 ). Other independent covariates for long-term survival (Table 8) included age, female gender, nondialysis renal failure, heart failure, lower ejection fraction, coronary artery disease requiring $\mathrm{CABG}$, endocarditis, preoperative stroke, diabetes, and chronic lung disease.

\section{DISCUSSION}

It has been estimated that approximately $50 \%$ of deaths in patients with ESRD occurs from cardiovascular disease. ${ }^{4}$ Although it has been appreciated that the 2-year survival rate in the dialysis population after a diagnosis of peripheral vascular disease is approximately $40 \%$, after cerebrovascular accident is $30 \%$, after congestive heart failure is $42 \%$, and after coronary revascularization is $45 \%$, the outcomes after cardiac valve surgery have not been so clearly defined. ${ }^{4}$ Most published series regarding cardiac surgical procedures for patients with dialysis-dependent ESRD have included a heterogenous population of patients undergoing isolated CABG, isolated valve surgery, or valve surgery with concomitant CABG. ${ }^{7,8,10,12-14,16,17}$ The present series differs in that we did not include any patients undergoing isolated CABG; because all patients underwent at least one valve surgery. In the present series, concomitant CABG was noted in $33 \%$ of the patients without preoperative dialysis compared with $29 \%$ with dialysis. In concordance with

TABLE 4. Adjusted odds ratios for in-hospital outcomes

\begin{tabular}{lcccc}
\hline \multicolumn{1}{c}{ Complications } & $\begin{array}{c}\text { No preoperative } \\
\text { dialysis }(\mathbf{n}=\mathbf{5 0 8 4})\end{array}$ & $\begin{array}{c}\text { Preoperative } \\
\text { dialysis }(\mathbf{n}=\mathbf{2 2 4})\end{array}$ & $\begin{array}{c}\text { Unadjusted } \\
\boldsymbol{P} \text { value }\end{array}$ & $\begin{array}{c}\text { Adjusted odds } \\
\text { ratios (95\% CI) }\end{array}$ \\
\hline In-hospital mortality & $263(5.2)$ & $41(18.3)$ & $<.001$ & $1.80(1.09-2.97)$ \\
Stroke & $151(3.0)$ & $14(6.3)$ & .006 & $1.11(0.53-2.31)$ \\
Myocardial infarction & $24(0.47)$ & $3(1.34)$ & .074 & $1.47(0.23-9.35)$ \\
MACCE & $394(7.8)$ & $48(21.4)$ & $<.001$ & .021 \\
\hline
\end{tabular}

Data presented as numbers (\%), unless otherwise noted. $C I$, Confidence interval; MACCE, Major adverse cardiac and cerebrovascular events. 
TABLE 6. Survival estimates by dialysis status

\begin{tabular}{lcc}
\hline \multicolumn{1}{c}{ Variable } & No preoperative dialysis $(\mathbf{n}=\mathbf{5 0 8 4})$ & Preoperative dialysis $(\mathbf{n}=\mathbf{2 2 4})$ \\
\hline Median survival (y) & $12+$ & 1.78 \\
1-Year survival (SE), number left at risk & $89.5 \%(0.4 \%), \mathrm{n}=3985^{*}$ & $59.2 \%(3.4 \%), \mathrm{n}=105$ \\
3-Year survival (SE), number left at risk & $84.4 \%(0.5 \%), \mathrm{n}=2887 *$ & $42.3 \%(3.7 \%), \mathrm{n}=48$ \\
5-Year survival (SE), number left at risk & $78.4 \%(0.7 \%), \mathrm{n}=1949 *$ & $28.9 \%(4.1 \%), \mathrm{n}=18$ \\
10-Year survival (SE), number left at risk & $63.9 \%(1.1 \%), \mathrm{n}=530^{*}$ & $19.6 \%(4.9 \%), \mathrm{n}=1$ \\
\hline
\end{tabular}

$S E$, Standard error. $* P<.001$.

published series, we also revealed significant preoperative comorbid characteristics in those patients with dialysisdependent renal failure. It is without doubt that the increased incidence of these variables lead to increased in-hospital morbidity and mortality. 7,8,10,12-14,16,17

In a retrospective review of 245 dialysis-dependent patients undergoing cardiac surgery at a single institution during an 8-year period, Rahmanian and colleagues ${ }^{16}$ have shown that patients with ESRD had an in-hospital mortality rate that was 3.7 times greater than that of nondialysis patients $(12.7 \%$ vs $3.9 \%)$. An examination by surgery type found that the mortality rate for isolated/multiple valve procedures was $17.1 \%$ compared with $12.8 \%$ and $10.3 \%$ for valve/CABG and isolated CABG, respectively. Unlike the report by Rahmanian and colleagues, ${ }^{16}$ the present series only included patients undergoing at least one valvular operation. We demonstrated a similarly dramatic increase in the morbidity and mortality for valve procedures, with an in-hospital mortality rate for the dialysis group of $18.3 \%$ compared with a rate of $5.2 \%$ for the nondialysis group. Similarly, a multicenter retrospective review from Germany identified 522 patients with ESRD undergoing a variety of cardiac surgical procedures; including $192(36.8 \%)$ with valve plus concomitant CABG. ${ }^{12}$ The patients in the ESRD group had a 30-day mortality rate of $11.5 \%$ and an overall survival rate at 5 years of $41.5 \%$, with the patients with isolated CABG

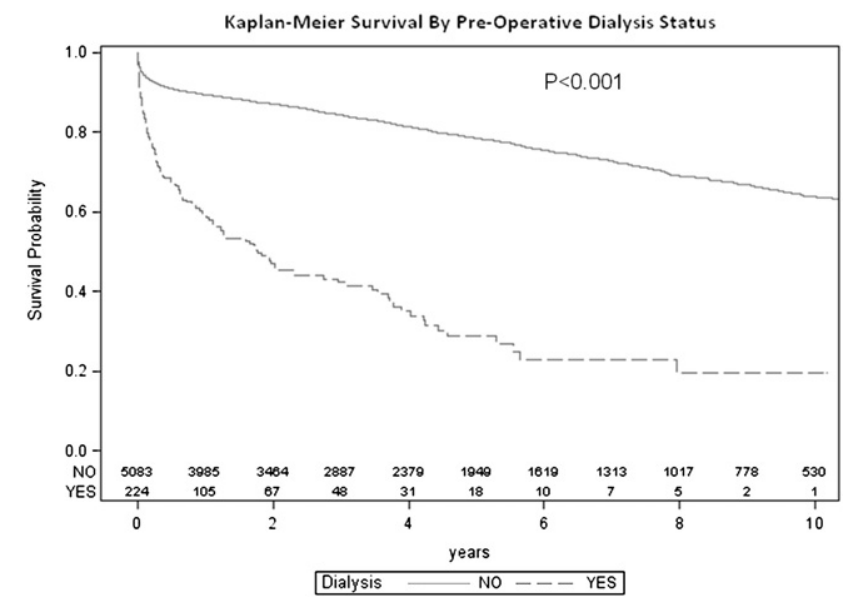

FIGURE 1. Kaplan-Meier survival estimates for all patients by preoperative dialysis status $(P<.001$ comparing groups). demonstrating improved survival compared with those receiving valve plus concomitant CABG. Despite the improvements in the perioperative treatment of patients undergoing valve surgery, those patients requiring dialysis for ESRD continue to have a three- to fourfold increase in in-hospital mortality.

It has been noted that the average survival rate of patients from the time of dialysis was started was $52 \%$ at 3 years and $33 \%$ at 5 years. ${ }^{18}$ This aspect is critically important as we evaluate the mid- and long-term mortality in patients with dialysis-dependent chronic renal failure undergoing cardiac surgery. ${ }^{12,14,16,17}$ Although it is difficult to ascertain the survivability of a patients with ESRD who does not undergo the required cardiac surgical procedure, in the present series, we noted a 5 -year overall survival rate of $29 \%$. Rahmanian and colleagues ${ }^{16}$ noted an estimated 5 -year survival rate of $39 \%$ in a series of 245 heterogenous patients undergoing cardiac surgery. In a series of 192 patients, Bechtel and colleagues ${ }^{12}$ noted an overall survival rate at 5 years of $41.5 \%$, with patients undergoing isolated CABG demonstrating improved survival compared with those undergoing valve plus concomitant CABG. In that study, they showed that the determinants of long-term mortality included emergency surgery, diabetes mellitus, age at surgery, and number of allogenic transfusions. Subsequent renal transplantation, the presence of sinus rhythm, and the use of the internal thoracic artery were associated with

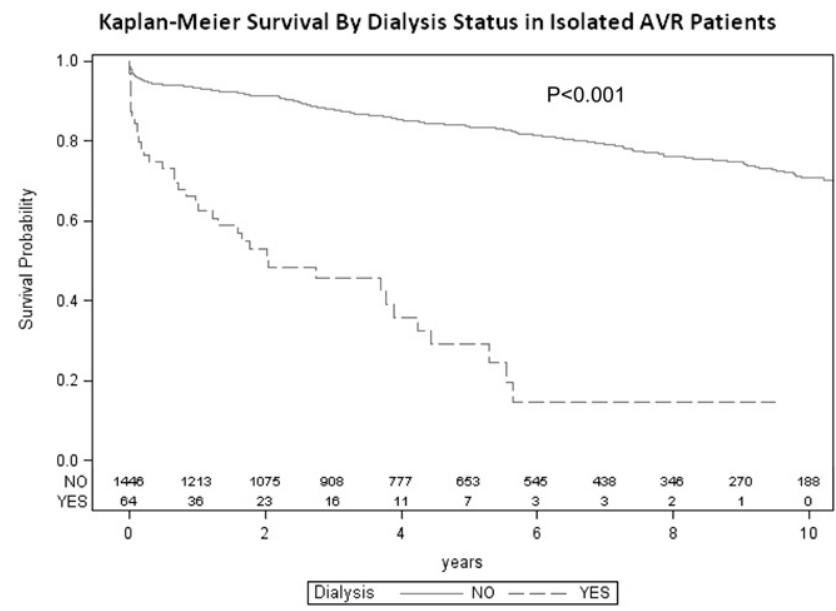

FIGURE 2. Kaplan-Meier survival estimates for isolated aortic valve replacement by preoperative dialysis status $(P<.001$ comparing groups). 


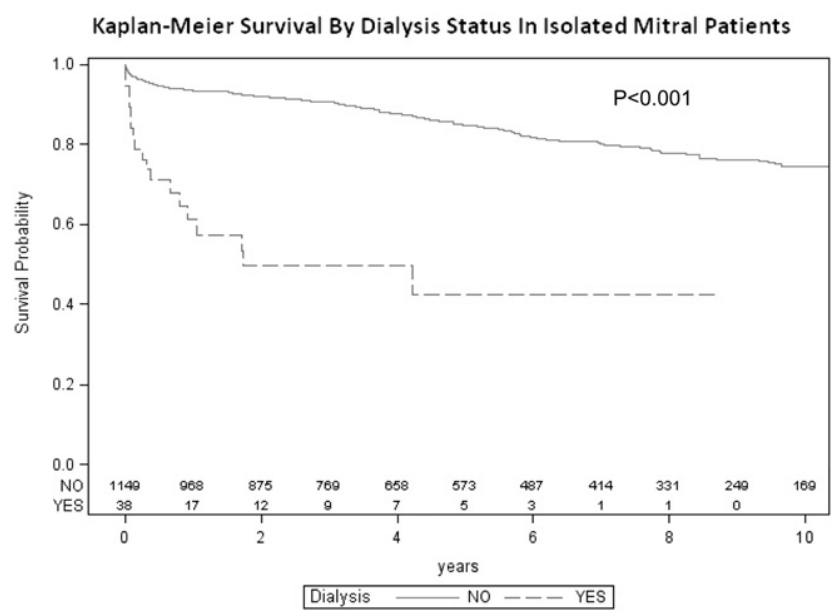

FIGURE 3. Kaplan-Meier survival estimates for isolated mitral valve procedures by preoperative dialysis status $(P<.001$ comparing groups).

longer survival. ${ }^{12}$ In a much smaller series, Kogan and colleagues ${ }^{14}$ showed an actuarial survival rate at 1 and 5 years of $59 \%$ and $21 \%$ for isolated aortic valve replacement and $44 \%$ and $33 \%$ for those undergoing other valve plus CABG procedures, respectively.

Perioperative stroke is a primary concern in these patients. Dialysis-dependent patients are known to have a more severe atherosclerotic disease burden than patients without ESRD. In the general ESRD population, a new stroke is an extraordinarily ominous occurrence. Patients with ESRD aged 75 to 84 years have a 1-year mortality rate of $20 \%$. A new stroke in that same age group is associated with increase in the annual mortality rate to $60 \% .{ }^{1}$ In the present series, the unadjusted stroke rates were $6 \%$ in dialysis patients compared with $3 \%$ in nondialysis patients $(P=.006)$. Once adjusted, we found no significant difference in the postoperative stroke risk between the two groups $\left(P=.79\right.$; Table 4). Similarly, Rahmanian and colleagues ${ }^{16}$ did not show an association between ESRD and

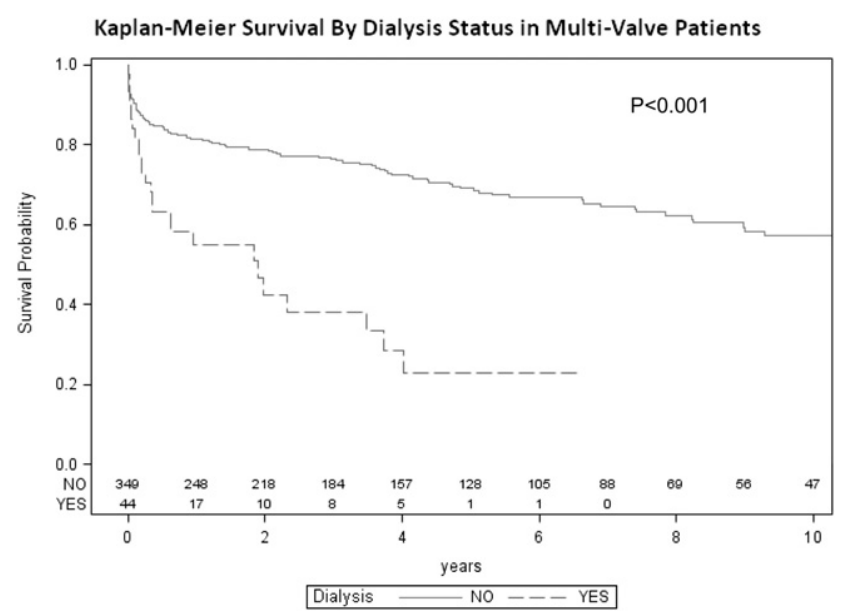

FIGURE 4. Kaplan-Meier survival estimates for multivalve procedures by preoperative dialysis status $(P<.001$ comparing groups).

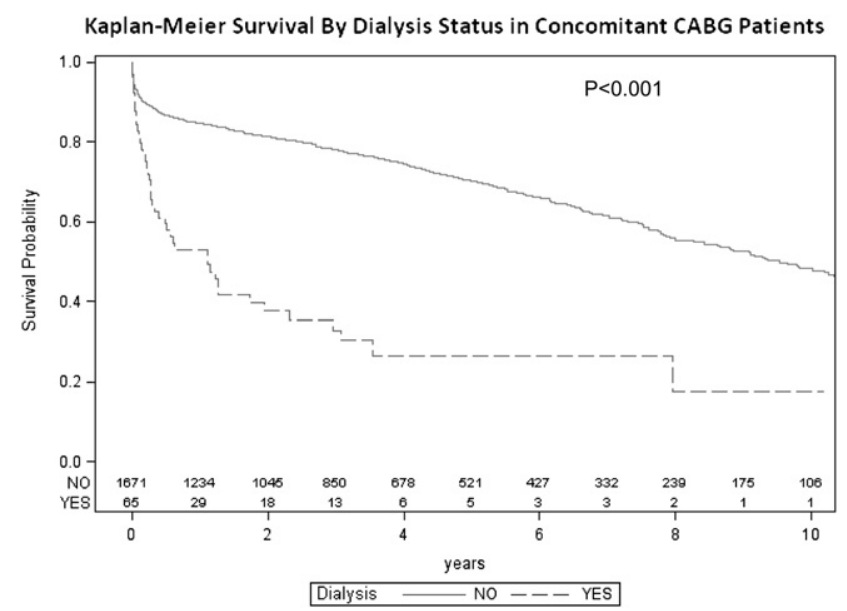

FIGURE 5. Kaplan-Meier survival estimates for any valve with concomitant coronary artery bypass grafting $(C A B G)$ by pre-operative dialysis status $(P<.001$ comparing groups $)$.

postoperative stroke $(3.3 \%$ in patients with ESRD vs $2.5 \%$ without ESRD). However, the patient populations were quite varied between the two studies, because $40 \%$ of their series included patients with isolated CABG, who have a lower risk of postoperative stroke risk compared with patients undergoing valve and concomitant CABG in the present series. Although we were unable to predict the stroke risk according to the aortic disease burden in the present data set, this, along with the inherent increased globalized small- and large-vascular atherosclerosis might be a plausible explanation for the increased stroke rate in this high-risk patient population.

\section{Study Limitations}

The present study was limited by its observational nature and the inherent limitations of a retrospective database study. Although we controlled for confounding variables using logistic regression analysis, it is likely that all factors influencing selection bias were not accounted for in the present analysis. Furthermore, the heterogeneity of the study population could make it difficult to draw broad conclusions from these data. Although survival with dialysis has improved during the past 20 years, it seems that most of the gains have occurred within the first few years of treatment. In the present study, we are unable to quantify how long before admission, the patient's dialysis had been initiated. It is intuitive to believe that those patients who were receiving dialysis for years versus months would have had

TABLE 7. Adjusted survival estimates for long-term survival

\begin{tabular}{lcc}
\hline \multicolumn{1}{c}{ Estimate } & HR $(\mathbf{9 5} \%$ CI $)$ & $\boldsymbol{P}$ value \\
\hline Crude estimate (no adjustment) & $4.67(3.88-5.62)$ & $<.001$ \\
Age-adjusted estimate & $6.54(5.41-7.89)$ & $<.001$ \\
Full adjustment & $2.34(1.83-2.99)$ & $<.001$ \\
\hline
\end{tabular}

HR, Hazard ratio; $C I$, Confidence interval. 
TABLE 8. Significant preoperative predictors of long-term survival from multivariate survival analysis

\begin{tabular}{llr}
\hline \multicolumn{1}{c}{ Preoperative variable } & \multicolumn{1}{c}{ HR $(\mathbf{9 5} \% \mathbf{C I})$} & $\boldsymbol{P}$ value \\
\hline Age & $1.04(1.032-1.043)$ & $<.001$ \\
Chronic lung disease & $1.28(1.07-1.53)$ & .006 \\
CVA & $1.54(1.30-1.82)$ & $<.001$ \\
EF & $0.99(0.988-0.997)$ & $<.001$ \\
Infectious endocarditis & $1.43(1.16-1.78)$ & $<.001$ \\
Female gender & $1.28(1.14-1.43)$ & $<.001$ \\
Heart failure & $1.25(1.11-1.41)$ & $<.001$ \\
Renal failure & $2.33(1.96-2.78)$ & $<.001$ \\
Renal failure requiring dialysis & $2.34(1.83-2.99)$ & $<.001$ \\
CAD requiring CABG & $1.34(1.19-1.51)$ & $<.001$ \\
Body mass index & $1.00(0.99-1.01)$ & .94 \\
Diabetes & $1.23(1.08-1.41)$ & .002 \\
\hline
\end{tabular}

$H R$, Hazard ratio; $C I$, Confidence interval; $C V A$, Cerebrovascular accident; $E F$, Ejection fraction; $C A D$, Coronary artery disease; $C A B G$, Coronary artery bypass grafting.

worse outcomes, and this is a current research investigation of our group. Finally, important operative variables were not available, such as the echocardiographic parameters. Although biologic versus mechanical valves were not evaluated in our study, Thourani and colleagues ${ }^{19}$ have noted similar mid- and long-term survival between valve types.

\section{CONCLUSIONS}

The present study represents one of the largest series to date to evaluate the outcomes of patients with ESRD after cardiac valve surgery. Although limited by its retrospective design, it illustrates the short-term morbidity and long-term mortality for this difficult patient cohort. Careful preoperative risk assessment and resource use should precede valve surgery in patients undergoing preoperative chronic dialysis for ESRD. Additional research investigation in the reduction of the high morbidity and mortality in patients with ESRD is warranted.

The authors from Emory University express their gratitude to staff members Kim Baio for project oversight, to Jean Walker and Susan Joyce for data abstraction, and to Deborah Canup for database management.

\section{References}

1. US Renal Data System. USRDS 2009 Annual Data Report: atlas of end-stage renal disease in the United States. National Institutes of Health, National Institute of Diabetes and Digestive and Kidney Diseases, Bethesda, MD, 2009. Available from http://www.usrds.org/adr.htm. Accessed November 15, 2009.

2. Kramer A, Stel V, Zoccali C, Heaf J, Ansell D, Grönhagen-Riska C, Leivestad T, Simpson K, Pálsson R, Postorino M, Jager K. An update on renal registry replacement therapy in Europe: ERA-EDTA registry data from 1997-2006. Nephrol Dial Transplant. 2009;24:3557-66.

3. Takami Y, Tajima K, Okada N, Fujii K, Sakai Y, Hibino M, Munakata H. Simplified management of hemodialysis-dependent patients undergoing cardiac surgery. Ann Thorac Surg. 2009;88:1515-9.

4. Collins AJ. Cardiovascular mortality in end-stage renal disease. Am J Med Sci. 2003;325:163-7.

5. Sarnak MJ, Levey AS, Schoolwerth AC, Coresh J, Culleton B, Hamm LL, et al. Kidney disease as a risk factor for development of cardiovascular disease: a statement from the American Heart Association Councils on Kidney in Cardiovascular Disease, High Blood Pressure Research, Clinical Cardiology, and Epidemiology and Prevention. Circulation. 2003;108:2154-69.

6. Barrett BJ, Parfrey PS, Morgan J, Barré P, Fine A, Goldstein MB, et al. Prediction of early death in end-stage renal disease patients starting dialysis. Am J Kidney Dis. 1997;29:214-22.

7. Brinkman WT, Williams WH, Guyton RA, Jones EL, Craver JM. Valve replacement in patients on chronic dialysis: implications for valve prosthesis selection. Ann Thorac Surg. 2002;74:37-42

8. Penta de Peppo A, Nardi P, De Paulis R, Pellegrino A, Forlani S, Scafuri A, Chiarello L. Cardiac surgery in moderate to end-stage renal failure: analysis of risk factors. Ann Thorac Surg. 2009;74:378-83.

9. Edwards FH, Peterson ED, Coombs LP, DeLong ER, Jamieson WRE, Shroyer ALW, Grover FL. Prediction of operative mortality after valve replacement surgery. J Am Coll Cardiol. 2001;37:885-92.

10. Horst M, Mehlhorn U, Hoerstrup SP, Suedkamp M, Rainer de Vivie E. Cardiac surgery in patients with end-stage renal disease: 10 year experience. Ann Thorac Surg. 2000;69:96-101.

11. Filsoufi F, Rahmanian PB, Castillo JG, Silvay G, Carpentier A, Adams DH. Predictors and early and late outcomes of dialysis-dependent patients in contemporary cardiac surgery. J Cardiothorac Vasc Anesth. 2008;22:522-9.

12. Bechtel JFM, Detter C, Fischlein T, Krabatsch T, Osswald BR, Riess FC, Scholz F, Schönburg M, Stamm C, Sievers HH, Bartels C. Cardiac surgery in patients on dialysis: decreased 30-day mortality, unchanged overall survival. Ann Thorac Surg. 2008;85:147-53.

13. Zimmet AD, Almeida A, Goldstein J, Shardey GC, Pick AW, Lowe CE Jolley DJ, Smith JA. The outcome of cardiac surgery in dialysis-dependent patients. Heart Lung Circ. 2005;14:187-90.

14. Kogan A, Medalion B, Kornowski R, Raanani E, Sharoni E, Stamler A, et al. Cardiac surgery in patients on chronic hemodialysis: short and long-term survival. Thorac Cardiovasc Surg. 2008;56:123-7.

15. Yamamura M, Mitsuno M, Tanaka H, Kobayashi Y, Ryomoto M, Nishi H, et al Risk factors for open heart surgery in hemodialysis patients. Gen Thorac Cardiovasc Surg. 2009;57:235-8.

16. Rahmanian PB, Adams DH, Castillo JG, Vassalotti J, Filsoufi F. Early and late outcome of cardiac surgery in dialysis-dependent patients: single center experience with 245 consecutive patients. J Thorac Cardiovasc Surg. 2008;135:915-22.

17. Witczak B, Hartmann A, Svennevig JL. Multiple risk assessment of cardiovascular surgery in chronic renal failure patients. Ann Thorac Surg. 2005;79:1297-302.

18. Byrne C, Vernon P, Cohen JJ. Effect of age and diagnosis on survival of older patients beginning chronic dialysis. JAMA. 1994;271:34-6.

19. Thourani VH, Sarin EL, Keeling WB, Kilgo PD, Guyton RA, Dara AB, et al. Long-term survival for patients with preoperative renal failure undergoing bioprosthetic or mechanical valve replacement. Ann Thorac Surg. 2011;91:1127-34. 